\title{
Mapeamento dos esforços dos principais grupos de pesquisa sobre zika vírus na UNICAMP
}

\author{
Carla Rodrigues Landim*, André Luiz Sica de Campos
}

\section{Resumo}

Esta pesquisa apresenta os esforços feitos pelos principais grupos de pesquisa da Universidade Estadual de Campinas (UNICAMP) na produção de conhecimento sobre o vírus Zika. O objetivo do projeto é caracterizar a capacidade de pesquisa dos grupos acerca do tema. O método para o desenvolvimento da investigação se desdobrou-se em duas fases, a primeira consiste na identificação dos grupos de pesquisa relacionados ao tema Zika vírus existententes na UNICAMP, através do site da universidade e do cruzamento com os grupos cadastrados nas plataformas Diretório de Grupos de Pesquisa do CNPq, Biblioteca Virtual FAPESP e Rede Zika. A segunda fase fundamentou-se na identificação e caracterização dos cinco grupos mais relevantes com base no número de membros dos grupos, número de publicações e patentes, auxílios recebidos e número de orientações feitas pelos docentes responsáveis pelos grupos.

\section{Palavras-chave:}

Pesquisa; Zika vírus; Unicamp

\section{Introdução}

Diante da epidemia do Zika vírus ocorrida em 2015 e 2016 o Brasil, e de seu impacto principalmente nos recém-nascidos vivos de mulheres que contraíram a doença, e do pouco conhecimento acerca do tema, a Universidade Estadual de Campinas (UNICAMP) realizou e tem realizado esforços de pesquisa neste tema. A partir da criação de uma rede de pesquisa, fomentando publicações e depósitos de patentes sobre o tema. A Universidade possui uma plataforma dentro do site do Sistema de Bibliotecas da Unicamp, que concentra todos os conteúdos científicos especializados a respeito do mosquito transmissor Aedes aegypti e do vírus Zika.

A partir desse cenário, e da postura da Unicamp frente a epidemia do Zika vírus o presente trabalho postula como questão de estudo: quais têm sido os esforços de pesquisa realizados pela UNICAMP no tema do vírus Zika? Como resultado esperado, antecipa-se que tenha ocorrido um maior interesse destes grupos sobre o tema específico do Zika vírus no período entre 2015 e 2016, quando a doença ganhou maior visibilidade junto ao público.

\section{Resultados e Discussão}

A pesquisa realizada utilizou, inicialmente, como metodologia de busca de grupos o cruzamento de informações obtidas no site da Biblioteca Virtual FAPESP de auxílios concedidos relacionados ao tema do Zika vírus, com os sites dos beneficiários presentes na página da Unicamp. Nessa primeira etapa foi possível identificar que existe uma defasagem de informações a respeito dos grupos de pesquisa que cada instituto da Unicamp possui, uma vez que nem todos os institutos possuíam informações a respeito do que o grupo pesquisa, tais como seus membros e data de criação.

Posteriormente foi realizado o cruzamento de beneficiários de auxílio da Unicamp relacionados ao tema Zika, obtidos no site Biblioteca Virtual FAPESP1, com o Diretório de Grupos de Pesquisa CNPq². Foi realizado ainda uma busca apenas no Diretório de Grupos de Pesquisa CNPq com as palavras-chave Zika, dengue e Chikungunya. Ao final do levantamento foram identificados 24 grupos relacionados ao tema Zika, dengue e Chikungunya na Unicamp.
Após o levantamento foi realizada a caracterização dos grupos contendo: o nome do grupo, seu líder, o número de membros, o número de publicações dos líderes no período de 2014 a 2018, o número de patentes geradas pelos líderes, auxílios obtidos no período de 2014 a 2018 e orientações realizadas pelos líderes todos entre 2014 a 2018. Com base nessas informações determinou-se os cinco grupos mais relevantes da Unicamp relacionadas ao tema Zika (tabela 1 ).

Tabela 1. Cinco grupos de pesquisa sobre zika mais relevantes.

\begin{tabular}{|l|l|}
\hline \multicolumn{1}{|c|}{ Nome do Grupo } & \multicolumn{1}{c|}{ Líder } \\
\hline $\begin{array}{l}\text { Lab. de Estudos de Vírus } \\
\text { Emergentes }\end{array}$ & José Luiz Proença Módena \\
\hline $\begin{array}{l}\text { Lab. Innovare de } \\
\text { Biomarcadores }\end{array}$ & Rodrigo Ramos Catharino \\
\hline Lab. de Virologia Animal & Clarice W. Arns \\
\hline $\begin{array}{l}\text { Lab. de Doenças } \\
\text { Tropicais }\end{array}$ & $\begin{array}{l}\text { Fabio Trindade Maranhão } \\
\text { Costa }\end{array}$ \\
\hline $\begin{array}{l}\text { Estudos Sociais da } \\
\text { Ciencia e da Tecnolocia }\end{array}$ & $\begin{array}{l}\text { Maria Conceição da Costa e } \\
\text { Lea Maria Leme Strini Velho }\end{array}$ \\
\hline
\end{tabular}

\section{Conclusões}

A partir da pesquisa realizada foi possível identificar que não houve a criação de grupos voltados exclusivamente para a pesquisa sobre Zika. Os esforços realizados a cerca do tema foram realizados por grupos já existentes na UNICAMP.

\section{Agradecimentos}

Agradeço ao CNPq pela concessão da bolsa para a realização dessa pesquisa, ao meu orientador Prof. Dr. André pela orientação e paciência ao longo do desenvolvimento e a amigos e familiares que de alguma forma agregaram para o desenvolvimento do projeto.

FAPESP. Biblioteca Virtual FAPESP. Disponível em: <https://bv.fapesp.br/pt/>. Acesso em: 05 mar. 2019

2 CNPQ. Diretório dos Grupos de Pesquisa no Brasil. Disponível em: <http://lattes.cnpq.br/web/dgp>. Acesso em: 02 abr. 2019. 